Pak. j. sci. ind. res. Ser. A: phys. sci. 2016 59(2) 109-113

\title{
Quality Variation Minimizer: A New Approach for Quality Improvement in Textile Industry
}

\author{
Muhammad Amin*, Muhammad Amanullah and Atif Akbar \\ Department of Statistics, Bahauddin Zakariya University, Multan, Pakistan \\ (received March 24, 2014; revised September 4, 2015; accepted October 9, 2015)
}

\begin{abstract}
The main theme of this research is to introduce a new technique for quality improvement in industries and services environment. The technique is called as quality variation minimizer (QVM), which is used to test and compare product quality among multiple data groups, i.e. machines, operators, and material etc. For the significant application, QVM is applied at Card department in spinning industry to determine yarn grains quality by different machines. Then comparison of QVM is made with other already developed techniques, i.e., coefficient variation (CV), sigma level etc. to determine yarn grains quality. From the results determined by t-test and chi square test, it has been found that QVM is an effective method to determine yarn grains quality with sample average near the target/demanded value as well as minimum variation.
\end{abstract}

Keywords: coefficient of variation, quality variation minimizer, sigma level, yarn grains quality

\section{Introduction}

Quality is the only key to survive any organization or company for a certain product or services. Quality means fitness for use or to meet the customer needs and satisfaction. In this situation, quality improvement activities have become a part of the business culture and a way of life (Gijo and Rao, 2005).

Across all types of industries, a well-known fact is that 'process and product variation' is the strongest factor affecting the product and process costs, process yield, product quality and customer satisfaction (Hild et al., 2000). During the past half of the century, various tools, i.e. statistical process control (SPC), quality circles (QC), total quality management (TQM), benchmarking, quality management system (QMS), enter resource planning (ERP) packages, Kaizen and Six Sigma have been developed for quality improvements and customer satisfaction (Antony et al., 2005; Dedhia, 2005; Montgomery, 2005).

Nowadays, billions of dollar are spent annually on good quality products in the world. In order to remain in the main stream of global competition, market manufacturers have to produce good quality products in various fields, i.e. health, the internet, textile, food etc. (Dhillon, 2007). In 2000, World fiber production was predicted 50 million tonnes (Clapp et al., 2001). In the textile industry, to ensure the product quality, quality control is necessary. Statistical quality control (SQC) was first time used in

*Author for correspondence; E-mail: ma_amin15@yahoo.com the yarn manufacturing industry in the late 1940s until 1950 (Clapp et al., 2001). In 1981, Milliken \& the Company (Textile Company) applied TQM in the company to meet the customer demands. Currently, there are 30,000 approximately textile-related companies in the United States, of which mostly use TQM tools for reducing cost and enhancing customer satisfaction (Mukhopadhyay and Ray, 2006). Mukhopadhyay and Ray (2006) applied Six Sigma to reduce yarn packing defects and they had the techniques of Six Sigma i.e., control chart, sigma level, MSA, regression, etc. Feili and Fekraty (2010) constructed the control charts on the basis of probability and fuzzy theory to monitor the yarn quality. They have found that fuzzy theory performs better than probability theory for monitoring product quality. Maros et al. (2011) applied control charts on chenille yarn defect types to see the variations.

Textile industry and its markets both are so complex and the customer is always demanding for better quality of textile products and on time delivery with minimum cost. To satisfy these challenges, companies are implementing SQC techniques for their customer satisfactions (Das, 2013). Acceptable quality is identified by the end user while fabric makers are the main user of yarn (Lord, 2003). In textile spinning industry, quality is valued by utilizing the parameters yarn count (NEC), count coefficient of variation (CV\%) or evenness (consistency), strength, CLSP, TPI (twist per inch), uniformity (Um\%), thin, thick places and so on. Yarn quality consistency is measured by variance, standard deviation or $\mathrm{CV}$ of 
the yarn quality parameter according to yarn product (Lord, 2003). One of the most important prerequisites for a spinner is to keep the average count and count variation within control. Most customers are interested in average count, counts CV\%, average CLSP and average single yarn strength over a specified yarn length. Most important parameter for measuring the yarn quality is the yarn strength because fabric durability and structure completely depend on yarn strength (Lord, 2003). Modern high performance machine in knitting and weaving mills require a constant yarn quality. Most of the successful spinning mills have to produce the demanded quality in close cooperation with knitter and weavers through most constant and cost-efficient manner. In parliamentary law to predict yarn behaviour, it is not sufficient merely to use individual quality characteristic, i.e. $\mathrm{CV} \%$ for the valuation of a narration. Because CVs does not discriminate between the sources of erroneous beliefs, then alternative methods are required for measuring yarn quality (Lord, 2003).

Reliable and accurate tools invention are necessary for evaluating the product quality. Customers are always demanding excellent product quality with a process average near the target (Demand) with minimum variation. Now, the problem is arising how to measure the process quality to meet the customer demand with minimum variation. In the present study a new technique Quality Variation Minimizer (QVM) has been introduced to measure the product quality. The principal objectives of QVM are as follows:

i. To predict product quality,

ii. To compare different brands/companies/departments, product quality,

iii. To detect a minimum and maximum product quality variation.

This QVM was applied in the textile industry to compare machines quality in terms of yarn grains quality.

\section{Materials and Methods}

Data and company. The data are taken from the Mehr Dastgir Spinning (MDS) Mills Ltd. Multan, Pakistan. The MDS manufacturing the following yarn products, i.e., $7 / 1$ s, $10 / 1$ s and Super $40 / 1$ s. A sample from the carding department for product 40/1s was taken which is nominated fine yarn to produce various types of clothes. The spinning industry for yarn manufacturing contains the following departments: mixing, blow room, carding, drawing (breaker and finisher), simplex, ring and autocone. The card is the heart of spinning industry and variation arises due to material, machine, man, and the environment. Therefore, the sample of grains/yard from the card machine wise was taken and detected which machine produce excellent quality with minimum variation and which has maximum variation. In this spinning industry, 22 card machines were sets in card department, however, machine Card MK5-12 was not in working condition when the samples from this industry of these machines were collected.

Methods. Different statistical tools were used for measuring the required yarn quality. These tools include mean, standard deviation, coefficient of variation $(\mathrm{CV})$, sigma level, QVM (our proposed technique), T-test, chi square test with respective p-values. The formulation of sigma level, process capability and QVM (proposed technique) methods are given as under:

Sigma level. A statistical tool which is used to measure the process quality level to meet the customer requirement, which is also a technique of six sigma and very important tool for measuring the product quality. Sigma level is grounded along the voice of customer, process average and process variation (standard deviation).

Six Sigma is implemented at textile spinning mills of India, reduction in delay procurement of material that results sigma level increase from 1.80 to 2.4 and yield improved from $62-76 \%$ (Das, 2005). Six Sigma is implemented in textile industry to reduce dying shade variation and the sigma level is increased from 0.81 to 2.34 , saving annually over $\$ 40,000$ (Das et al., 2007).

Mathematically sigma level is defined as:

Sigma level $=$ process shift $+\min \left[\left(\frac{\mathrm{USL}-\overline{\mathrm{x}}}{\hat{\sigma}}\right),\left(\frac{\overline{\mathrm{x}}-\mathrm{LSL}}{\hat{\sigma}}\right)\right]$

where:

$\mu=$ target or demanded average; $\overline{\mathrm{x}}=$ the estimated process mean; $\hat{\sigma}=$ the estimated standard deviation from the process; USL $=$ the upper specification limit and LSL $=$ the lower specification limit.

Generally the process shift is 1.5 from the target i.e., $\mu$. Because some quality standards on average are $\mu \pm$ $3 \sigma$ and at one side, may be left or right, the distance of target values. In other words, we can take the process shift allowed variation given by the customer is on 
either side from the target value is 1.5 for further detail about process shift of 1.5 (Bothe, 2002).

Sigma level $=1.5+$ minimum $\left(\frac{\mathrm{USL}-\overline{\mathrm{x}}}{\hat{\sigma}}, \frac{\overline{\mathrm{x}}-\mathrm{LSL}}{\hat{\sigma}}\right)$

There is direct relationship between sigma level and customer expectations. So higher sigma level results better customer expectations, meaning the fewer defects are produced in the process. Sigma level is inversely proportional to process standard deviation. It shows that if process standard deviation increases, then the sigma level is decreased. Similarly, if process standard deviation is decreased, then the sigma level is increased. Our main objective to minimize the process variation is the main reason to use sigma level to measure the process quality for comparison purposes (Breyfogle, 1999).

Process capability. Another measure for determining the product quality is process capability $\left(\mathrm{C}_{\mathrm{p}}\right) . \mathrm{C}_{\mathrm{p}}$ measures customer specifications in terms of acceptable spread or dispersion, without reference to the target value (Ehrlich, 2002). $\mathrm{C}_{\mathrm{p}}$ mathematically is defined as:

$$
\mathrm{C}_{\mathrm{p}}=\frac{\mathrm{USL}-\mathrm{LSL}}{\hat{\sigma}}
$$

The difference is the tolerance of manufacturing process and the voice of the customer.

According to Keller (2011), Montgomery (2005) and Park (2003) the interpretation of $\mathrm{C}_{\mathrm{p}}$ is as follows:

If $\mathrm{C}_{\mathrm{p}}<1$, then the process variation is greater than allowable variation and more defective items are produced

If $\mathrm{C}_{\mathrm{p}}=1$, it indicates the sample variation exactly equals the allowable variation (i.e. tolerance)

If $\mathrm{C}_{\mathrm{p}}>1$, then the process variation is smaller than allowable and less defective items are produced.

The main limitation of this technique like $\mathrm{CV}$ is that it does not see how process mean is away from the target value. It just only sees the voice of the customer and process standard deviation.

Quality variation minimizer. As the limitation of $\mathrm{CV}$ and $\mathrm{C}_{\mathrm{p}}$ techniques is discussed to assess the product quality, now the question arises how these limitations are swept to get reliable results regarding the product quality and also how to measure the process quality to meet the customer demand with minimum variation and process average near the target? Here a new technique has been introduced which has been called Quality Variation Minimizer (QVM) to measure the product quality. QVM mathematically is defined as:

$$
\mathrm{QVM}=\mathrm{Z}_{\frac{\alpha}{2}} \times \hat{\sigma}+\frac{|\overline{\mathrm{x}}-\mu|}{\mathrm{n}}
$$

where:

$\mathrm{Z}_{\frac{\alpha}{2}}=$ the critical value of the normal distribution at a specified level of significance. QVM is affected by level of significance, the absolute distance between process average and the target value, process standard deviation and the sample size. The smaller the value of alpha indicates more reliable QVM results as compared to QVM at larger alpha. As in the literature there are standard quality testing tools, i.e. $\mathrm{C}_{\mathrm{p}}$, sigma level. This proposed method QVM has been proved practically that it performs in a better way than already developed method with simple and minimum computation.

\section{Results and Discussion}

In Table 1, studies of yarn grains/yards quality of different machines have been presented alongwith performance of QVM. A comparison among QVM with $\mathrm{SD}, \mathrm{CV}, \mathrm{C}_{\mathrm{p}}$ and sigma level is depicted here.

From Table1, it is clear that on the basis of smaller standard deviation and $\mathrm{CV}$, the best quality was given by machine Card MK5-19, while T-test says that process average grains do not meet the customer needs and also chi-square test indicates that the process variation is not acceptable. Now, considering the machine Card MK5-03, Card MK5-18 and Card MK5-22, these have the process average near the target but their $\mathrm{CV}$ is so large. Similar results are given by $\mathrm{C}_{\mathrm{p}}$ because it depends only on process standard deviation. On the other hand, sigma level and QVM observes both target and process variation. Table 1 also shows that sigma level is maximum where QVM is minimum and t-test is accepted. This indicates that the process average met the target or demanded value and also variation by chi-square test was minimum of machine Card MK5-16 as compared to other machines and therefore, considered as the best machine for producing a good quality grains. On the other hand bad quality was produced by Card MK5-01 as its sigma level was minimum and QVM was maximum. This machine also needed to be checked for the mechanical faults. There are some situations where $\mathrm{CV}$, SD and QVM are minimum while sigma level, $C_{p}$ is maximum but it is not always true. QVM depends on 
level of significance, absolute distance between process average and target value and process standard deviation. As the greater value of the level of significance may provide similar results as other groups. So smaller value gives more cleared results of QVM to discriminate the product quality among the groups. QVM value will move in the same direction with process standard deviation and the absolute distance between average and target value. These relationships are also shown in correlation in Table 2. The significance of this proposed technique is that it has been applied in the textile spinning industry and the results show that this technique is comparatively better than $\mathrm{CV}$. So this proposed technique may be used in other manufacturing industries to compare the product quality by different machines, operators, temperature level, humidity level etc.

Table 1. Card department yarn grains/yards quality analysis by machines

\begin{tabular}{|c|c|c|c|c|c|c|c|c|c|c|c|c|c|c|c|}
\hline & Depa & ment & & Card & & \multirow{3}{*}{\multicolumn{3}{|c|}{ Specification limits }} & USL & 61.5 & \multirow{2}{*}{\multicolumn{3}{|c|}{$\begin{array}{l}\text { Process shift } \\
\text { Level of significance }\end{array}$}} & \multicolumn{2}{|l|}{1.5} \\
\hline & \multirow{2}{*}{\multicolumn{5}{|c|}{ Grains/Yard machine wise analysis }} & & & & \multirow{2}{*}{$\begin{array}{l}\text { Target } \\
\text { LSL }\end{array}$} & 60 & & & & 0.05 & \\
\hline & & & & & & & & & & 58.5 & & \multicolumn{2}{|c|}{ Target SD } & \multicolumn{2}{|l|}{$\begin{array}{l}0.05 \\
0.6\end{array}$} \\
\hline & \multicolumn{6}{|c|}{ Descriptive and quality measuring statistics } & \multirow{2}{*}{\multicolumn{3}{|c|}{ Level of significance }} & & & & & \\
\hline \multirow[t]{2}{*}{ Machines } & Mean & SD & $\mathrm{CV}$ & $\mathrm{C}_{\mathrm{p}}$ & Sigma & Sample & & & & \multirow[t]{2}{*}{ T-test } & \multirow[t]{2}{*}{ P-value } & Deci- & & \multirow[t]{2}{*}{ P-value } & \multirow{2}{*}{$\begin{array}{l}\text { Deci- } \\
\text { sion }\end{array}$} \\
\hline & & & & & level & size & 0.1 & 0.05 & 0.01 & & & sio & square & & \\
\hline Card MK5-01 & 59.35 & 1.35 & 2.27 & 0.37 & 2.13 & 20 & 2.6025 & 3.2800 & 4.1252 & -2.15 & 0.0444 & NO & 95.841 & 0.0000 & NO \\
\hline Card MK5-02 & 59.95 & 0.72 & 1.21 & 0.69 & 3.5 & 86 & 1.1014 & 1.4600 & 1.9192 & -0.67 & 0.5065 & Yes & 123.664 & 0.0040 & NO \\
\hline Card MK5-03 & 60 & 1.09 & 1.82 & 0.46 & 2.87 & 82 & 1.5849 & 2.1300 & 2.8173 & -0.03 & 0.9776 & Yes & 267.654 & 0.0000 & NO \\
\hline Card MK5-04 & 60.28 & 0.81 & 1.34 & 0.62 & 3.01 & 79 & 1.4546 & 1.8600 & 2.3681 & 3.11 & 0.0027 & NO & 141.588 & 0.0000 & NO \\
\hline Card MK5-05 & 60.33 & 0.76 & 1.26 & 0.66 & 3.03 & 81 & 1.4367 & 1.8200 & 2.2965 & 3.94 & 0.0002 & NO & 128.658 & 0.0000 & NO \\
\hline Card MK5-06 & 60.3 & 0.87 & 1.44 & 0.58 & 2.89 & 82 & 1.5547 & 1.9900 & 2.5343 & 3.11 & 0.0026 & NO & 169.091 & 0.0000 & $\mathrm{NO}$ \\
\hline Card MK5-07 & 60.29 & 0.79 & 1.31 & 0.63 & 3.04 & 86 & 1.4308 & 1.8300 & 2.3235 & 3.35 & 0.0012 & NO & 147.356 & 0.0000 & NO \\
\hline Card MK5-08 & 59.88 & 0.99 & 1.65 & 0.51 & 2.9 & 81 & 1.5531 & 2.0500 & 2.6670 & -1.13 & 0.2616 & Yes & 215.92 & 0.0000 & NO \\
\hline Card MK5-09 & 59.88 & 0.92 & 1.54 & 0.54 & 2.99 & 83 & 1.4646 & 1.9300 & 2.5095 & -1.22 & 0.2259 & Yes & 194.751 & 0.0000 & NO \\
\hline Card MK5-10 & 59.91 & 0.87 & 1.45 & 0.57 & 3.12 & 88 & 1.3499 & 1.7800 & 2.3327 & -0.96 & 0.341 & Yes & 182.808 & 0.0000 & NO \\
\hline Card MK5-11 & 60.06 & 0.76 & 1.26 & 0.66 & 3.4 & 85 & 1.1614 & 1.5400 & 2.0158 & 0.79 & 0.4305 & Yes & 133.412 & 0.0000 & NO \\
\hline Card MK5-13 & 59.7 & 0.89 & 1.5 & 0.56 & 2.84 & 87 & 1.5955 & 2.0400 & 2.6041 & -3.15 & 0.0023 & NO & 190.323 & 0.0000 & NO \\
\hline Card MK5-14 & 60.37 & 0.95 & 1.57 & 0.53 & 2.69 & 69 & 1.7461 & 2.2200 & 2.8199 & 3.22 & 0.002 & NO & 170.576 & 0.0000 & NO \\
\hline Card MK5-15 & 60.18 & 0.79 & 1.32 & 0.63 & 3.16 & 81 & 1.3318 & 1.7300 & 2.2286 & 2.05 & 0.0434 & NO & 139.974 & 0.0000 & NO \\
\hline Card MK5-16 & 60.09 & 0.7 & 1.16 & 0.71 & 3.52 & 88 & 1.1011 & 1.4500 & 1.8917 & 1.16 & 0.2488 & Yes & 118.304 & 0.0140 & NO \\
\hline Card MK5-17 & 60.04 & 0.99 & 1.65 & 0.51 & 2.98 & 81 & 1.4709 & 1.9700 & 2.5890 & 0.33 & 0.7428 & Yes & 217.566 & 0.0000 & NO \\
\hline Card MK5-18 & 59.98 & 0.76 & 1.26 & 0.66 & 3.45 & 83 & 1.1188 & 1.5000 & 1.9753 & -0.24 & 0.8132 & Yes & 130.863 & 0.0000 & NO \\
\hline Card MK5-19 & 59.56 & 0.68 & 1.14 & 0.74 & 3.06 & 89 & 1.4263 & 1.7700 & 2.1926 & -6.16 & 0.0000 & NO & 112.431 & 0.0410 & NO \\
\hline Card MK5-20 & 59.69 & 0.94 & 1.58 & 0.53 & 2.76 & 65 & 1.6833 & 2.1600 & 2.7507 & -2.68 & 0.0094 & NO & 158.602 & 0.0000 & NO \\
\hline Card MK5-21 & 59.52 & 1.01 & 1.7 & 0.49 & 2.51 & 84 & 1.9423 & 2.4500 & 3.0845 & -4.32 & 0.0000 & NO & 235.576 & 0.0000 & NO \\
\hline Card MK5-22 & 59.97 & 1.1 & 1.84 & 0.45 & 2.83 & 81 & 1.6342 & 2.1900 & 2.8825 & -0.26 & 0.7925 & Yes & 271.193 & 0.0000 & NO \\
\hline
\end{tabular}

YES = no significant difference between process value and target value; $\mathrm{NO}=$ there is significant difference between process value and target value.

Table 2. Correlation matrix among quality measures

\begin{tabular}{llllllll}
\hline \hline & QVM & Mean & SD & CV & $\mathrm{C}_{\mathrm{p}}$ & Sigma level & ABS distance \\
\hline QVM & 1.0000 & -0.5171 & 0.9070 & 0.9098 & -0.8553 & -0.9688 & 0.6576 \\
Mean & -0.5171 & 1.0000 & -0.4419 & -0.4653 & 0.3642 & 0.4490 & -0.3826 \\
SD & 0.9070 & -0.4419 & 1.0000 & 0.9995 & -0.9768 & -0.8392 & 0.2797 \\
CV & 0.9098 & -0.4653 & 0.9995 & 1.0000 & -0.9754 & -0.8415 & 0.2862 \\
C & -0.8553 & 0.3642 & -0.9768 & -0.9754 & 1.0000 & 0.8224 & -0.2016 \\
Sigma level & -0.9688 & 0.4490 & -0.8392 & -0.8415 & 0.8224 & 1.0000 & -0.7053 \\
ABS distance & 0.6576 & -0.3826 & 0.2797 & 0.2862 & -0.2016 & -0.7053 & 1.0000 \\
\hline \hline
\end{tabular}

$\overline{\mathrm{ABS}}=$ absolute; $\mathrm{QVM}=$ quality variation minimizer; $\mathrm{CV}=$ coefficient of variation; $\mathrm{C}_{\mathrm{p}}=$ process capability. 


\section{Conclusion}

Different machines of card department in textile industry were studied and different quality measuring tools were used for checking the machines quality. Most of the spinning quality analyst uses only the $\mathrm{CV}$ for measuring the yarn quality. They say that the machine with minimum $\mathrm{CV}$ has better quality. From the $\mathrm{CV}$ formula, it was found that this is the ratio of process SD to the process mean. $\mathrm{CV}$ does not show the target mean but just gives the ratio between process standard deviation and mean. Similarly, the $\mathrm{C}_{\mathrm{p}}$ measurement only sees the process standard deviation and not the process mean. From the present results and discussion, it has come to the point that smaller the value of QVM results in larger quality level of yarn product and QVM is minimum where sigma level is maximum. This indicates that better quality of product is produced. QVM may also be preferred over CV for its computational ease. QVM technique seems to be so simple to use and can be considered as good as other techniques, i.e. regression and design of experiments, etc., in the industry to test the quality over the time to get quick and reliable results.

\section{References}

Antony, J., Kumar, M., Madu, C.N. 2005. Six sigma in small and medium sized UK manufacturing enterprises: Some empirical observations. International Journal of Quality \& Reliability Management, 22: 860-874.

Bothe, D.R. 2002. Statistical reason for the $1.5 \sigma$ Shift. Quality Engineering, 14: 479-487.

Breyfogle, F.W. 1999. Implementing Six Sigma: Smarter Solutions Using Statistical Methods, 1229 pp., $2^{\text {nd }}$ edition, Wiley Interscience, New York, USA.

Clapp, T.G., Godfrey, A.B., Greeson, D., Jonson, R.H., Rich, C., Seastrunk, C. 2001. Quality Initiatives reshape the textile industry. Quality Digest, October, http://www.qualitydigest.com/oct01/html/textile. html.

Das, A. 2013. Testing and statistical quality control in textile manufacturing. In: Process Control in Textile Manufacturing, A. Majumdar, A. Das, R. Alagirusamy and V. K. Kotari (eds.), pp. 41-78, Woodhead Publishing Series in Textiles: Number 131, New Dehli, India.

Das, P., Roy, S., Antony, J. 2007. An application of six sigma methodology to reduce lot-to-lot shade variation of linen fabrics. Journal of Industrial Textiles, 36: 227-251.

Das, P. 2005. Reduction in delay in procurement of materials using six sigma philosophy. Total Quality Management \& Business Excellence, 16: 645-656.

Dedhia, N.S. 2005. Six sigma basics. Total Quality Management \& Business Excellence, 16: 567-574.

Dhillon, B.S. 2007. Applied Reliability and Quality: Fundamentals, Methods and Procedures, 260 pp., $1^{\text {st }}$ edition, Springer Series in Reliability Engineering, Springer, London, UK.

Ehrlich, B.H. 2002. Transactional Six Sigma Servicing, Leveraging Manufacturing Concepts to Achieve World-Class Service, pp. 126-127, St. Lucie Press, Boca Raton London, New York, USA.

Feili, H.R., Fekraty, P. 2010. Comparing fuzzy charts with probability charts and using them in a textile company. The Journal of Mathematics and Computer Science, 1: 258-272.

Gijo, E.V., Rao, T.S. 2005. Six sigma implementationhurdles and more hurdles. Total Quality Management \& Business Excellence, 16: 721-725.

Hild, C., Sanders, D., Cooper, T. 2000. Six sigma on continuous processes: how and why it differs? Quality Engineering, 13: 1-9.

Keller, P. 2011. Six Sigma Demystified, pp. 326-327, $2^{\text {nd }}$ edition, McGraw-Hill, New York, USA.

Lord, P.R. 2003. Handbook of Yarn Production: Technology, Science and Economics, pp. 276-300, CRC Press, Woodhead Publishing Ltd., Cambridge, England.

Maros, T., Viladimir, B., Caner, T.M. 2011. Monitoring chenille yarn defects using image processing with control charts. Textile Research Journal, 81: 13441353.

Montgomery, C.D. 2005. Introduction to Statistical Quality Control, pp. 202-203, $5^{\text {th }}$ edition, John Wiley \& Sons Inc, New York, USA.

Mukhopadhyay, A.R., Ray, S. 2006. Reduction of yarn packing defects using Six Sigma methods: A case study. Quality Engineering, 18: 189-206.

Park, S.H. 2003. Six Sigma for Quality and Productivity Promotion, pp.18-23, Asian Productivity Series 32, Asian Productivity Organization, Tokyo, Japan. 